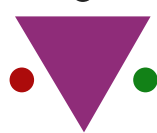

IJCRR

Section: Healthcare

Sci. Journal Impact

Factor: 6.1 (2018)

ICV: 90.90 (2018)

(c) (i) (9)

Copyright@IJCRR

\title{
A Study on Covid-19 Situation in Andhra Pradesh: Current Scenario and Projections
}

\section{Srinivasa Rao' ${ }^{1}$ Ch. Rajasekhar ${ }^{2}$, K. Santa Rao ${ }^{3}$}

'Department of ECE, GMR Institute of Technology, Rajam, Andhra Pradesh, lndia; 'Department of EECE, GITAM Institute of Technology, GITAM (Deemed to be University), Andhra Pradesh, India; ${ }^{3}$ Department of Mechanical Engineering, GMR Institute of Technology, Rajam, Andhra Pradesh, India.

\section{ABSTRACT}

Aim: Andhra Pradesh (AP) has seen a 20 times rise in COVID-19 cases soon after unlock and now stood in top five worst-hit states in India. The state which had 3,042 cases at the end of May, now has 69816 cases. Nearly, 65,000 cases were registered in just one and half month. The purpose of this study is to assess the current status of COVID-19 in Andhra Pradesh and to forecast the condition of future, which will help to strengthen management.

Methodology: AP daily health bulletin and Health, Medical and Family Welfare (HMFW) data are used for the estimation of the forecast from 25 March to 23 July 2020. The forecast data charts in Microsoft Excel are used to estimate the potential COVID-19 cases for the Andhra Pradesh State.

Results: Based on projected results, AP will cross 476534 cases by mid-September 2020. The proportion of positive cases out of tested samples in the state may go up to $30 \%$. The COVID-19 death toll in the state may cross the 5000 value. In summary, the projection says that the increasing trend in COVID cases may continue a few months, while the death toll may be kept low with proper medical planning.

Conclusion: The current situation in AP has put officials in alert to bring down the growth of COVID cases. Although several control measures are being taken by the government, still it needs to adapt intelligent strategies to better handle the pandemic.

Key Words: Andhra Pradesh, COVID-19, Disease, Scenario, Projection

\section{INTRODUCTION}

Coronavirus disease (COVID-19) is a recently identified infectious disease caused by a severe acute respiratory syndrome coronavirus 2 (SARS-CoV-2) ${ }^{1}$ Most COVID-19 affected people may have slight to medium respiratory disorders and they will be recovered without going for special treatment. Elderly people and those with specific medical problems such as cardiovascular disease, diabetes, chronic respiratory disorder and cancer appear to develop infectious complications. The coronavirus outbreak was detected on 31 December 2019 when China announced a cluster of pneumonia-related cases in Wuhan City, Hubei Province to the World Health Organization (WHO). Since then it has spread to many countries around the world, with the WHO declaring it a pandemic ${ }^{2}$. Today, India has the highest number of reported cases in Asia. After the United States and Brazil, it lists the third-largest number in the world with the cumulative number of reported cases exceeding the 100,000 marks on 19 May 2020 and 200,000 on 3 June $2020^{3}$. India's fatality rate is comparatively lower at $2.80 \%$ compared to the worldwide $4.7 \%$ by 6 July 2020. In India, Andhra Pradesh (AP) is in 5th place with the 69816 (as of 23 July 2020) confirmed cases ${ }^{4}$. A brief overview of the AP state and the motivation behind the work is presented in the following subsections.

\section{About Andhra Pradesh}

Andhra Pradesh is one of India's 29 states located on the southeast coast and is the eighth largest state with a total area of 160,205 sq. Km. According to the 2011 India census, the state is 10th position by population with $49,386,799$ inhabitants ${ }^{4}$. AP state was bifurcated from the north-western part on 2 June 2014, which led to the existence of a new Telangana state. According to the AP Reorganization Act 2014, Hyderabad remains the capital of both states AP and

\section{Corresponding Author:}

Dasari Srinivasa Rao, Department of ECE, GMR Institute of Technology, Rajam, Andhra Pradesh, India.

Email: srinivasa.dasari@gmail.com

ISSN: 2231-2196 (Print) ISSN: 0975-5241 (Online)

Received: 27.07 .2020

Revised: 12.08 .2020

Accepted: 28.08 .2020

Published: 08.09.2020 
Telangana for a duration of maximum 10 years. The Andhra Pradesh State is connected north by Chhattisgarh, north-east by Odisha, west by Telangana \& Karnataka, south by Tamil Nadu and east coast by the Bay of Bengal. Some of the key cities within the state are Visakhapatnam, Vijayawada, Tirupati, Rajahmundry, Guntur, Kakinada, Ongole, Nellore and Kurnool. High economic growth, long coastline, adequate power generation capacity and huge export capability are the crucial advantages of the state ${ }^{5}$. The physical, industrial and social infrastructure are the state's key sectors to attract investments from global players. Drugs and pharmaceuticals, agriculture and allied, petrol and chemicals, tourism are the key industrial sectors.

\section{Motivation}

Andhra Pradesh is India's sunrise state. It is well recognized as the 'Rice Bowl of India' for being a major producer of rice in India. The state is well linked by road and rail networks to other states. It is also linked with other countries through airways and seaports ${ }^{5}$. The state's first COVID-19 case was reported on 12 March 2020 at Nellore district. It was 24-year-old man returned from Italy. The second case was registered at Ongole on 15 March 2020 and identified as the man returned from London. The state reported its first COVID-19 death on 3 April 2020 at Vijayawada. It was a 55-year-old man who acquired a virus from his son. The state has seen a sudden increase in registered cases after the Delhi Markaz event in early March 2020. The first singleday spike is observed on 1 April 2020 with 67 positive cases. This has taken the count from 44 to 111. India has imposed nationwide lockdown in four phases which ended on 31 May 2020. From then on, the country started lifting lockdown in a phased manner. Now all the states have seen a rise in the number of cases due to the influx of migrant workers. As of 23 July 2020, the AP state has 69816 COVID-19 confirmed cases. The virus has spread in 13 districts of the state, of which Kurnool has the highest number of cases. Till May 2020, AP is in 11th position in COVID cases across the country, now it moved to 5 th place by overtaking five states. The rising trend in new cases put the government in tension and brought challenges to handle the pandemic. This made us study about the COVID-19 status at Andhra Pradesh state.

\section{Current COVID-19 Status at AP}

Figure 1 represents the tendency of cumulative positive cases in India and Andhra Pradesh as on 23 July 2020. The first positive in the country was identified on 30 Jan 2020, while in AP the first case is confirmed on 12 March 2020.

Figure 2 displays the tendency of cumulative deceased cases in India and Andhra Pradesh as on 23 July 2020. The first death in India happened on 13 March 2020. While in AP, the first COVID death was confirmed on 3 April 2020. The total death count of India is nearly 30000 cross mark on 23 July 2020. While the death count of AP is close 1000 cross mark.

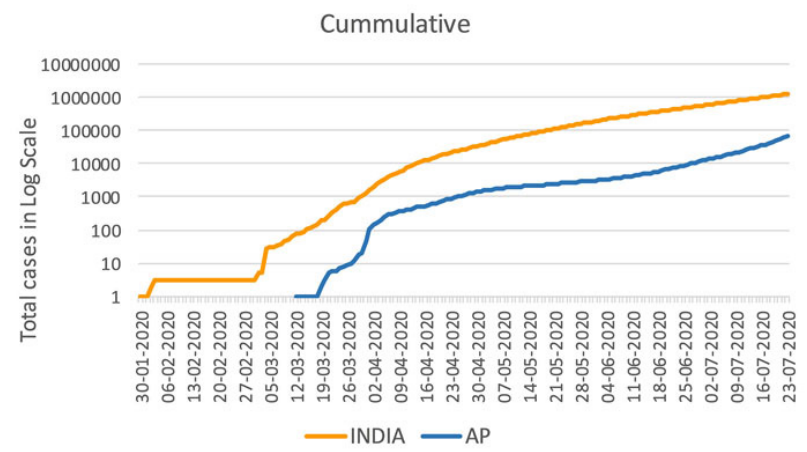

Figure 1: Covid-19 Positive Cases in India and $A P^{3,6}$.

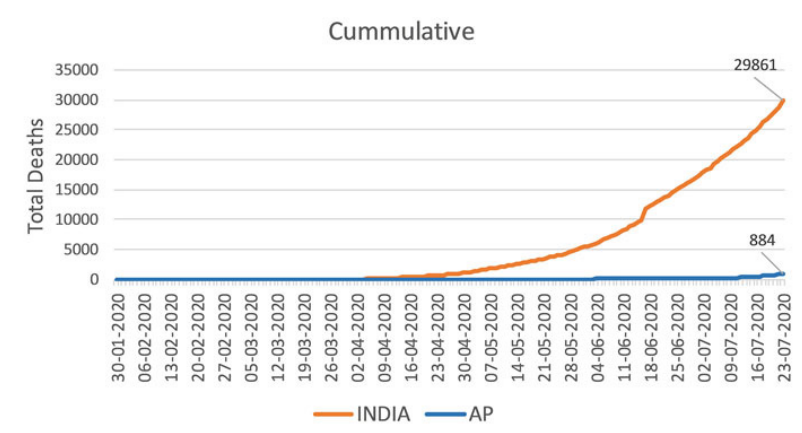

Figure 2: Covid-19 Death trend in India and $\mathrm{AP}^{3,6}$.

Figure 3 illustrates the district wise confirmed COVID cases across the AP as on 23 July 2020. Among them, East Godavari district tops in the number of cases with a total count of 10038. While Kurnool, Guntur and Anantapur districts hold second, third and fourth positions respectively. Earlier, northeast districts Srikakulam and Vizianagaram were green zones for many days. Now, they also started showing an increasing trend in registered positive cases. The main reason is due to the return of migrant workers in the nationwide unlock. Chittoor district being near to the Chennai region able to draw more number of cases. Cities like Vijayawada, Eluru, Rajahmundry, Kakinada, and Visakhapatnam are experiencing a surge in the number of cases due to dense population.

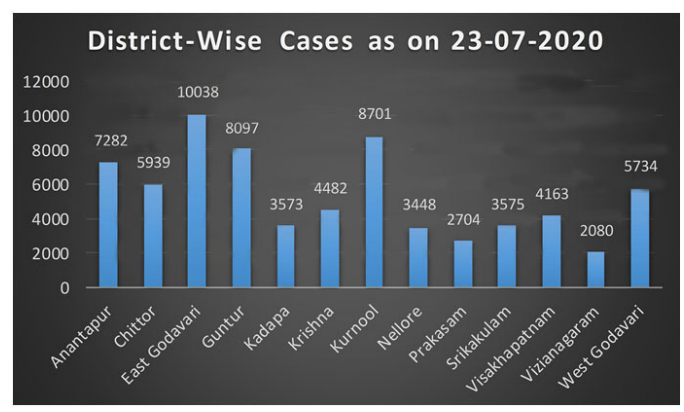

Figure 3: District-wise positive cases in $\mathrm{AP}^{6}$. 
Figure 4 represents the state-wide trend of positive cases during the lockdown and unlock phases. It is known that the Government of India had announced the first countrywide lockdown on 25 March 2020. The entire nation was under lockdown for four phases till 31 May 2020.

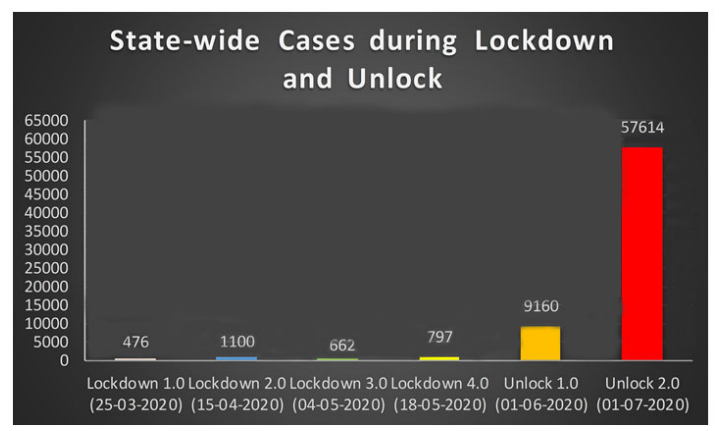

Figure 4: Total cases in AP during Lock and Unlock Phases ${ }^{6}$.

During the first phase of Lockdown 1.0, the total number of positive cases is only 476. In the second phase of Lockdown 2.0, it had seen the first cumulative spike of 1100 cases. Then, it well managed Lockdown 3.0 and Lockdown 4.0 with registered cases of 662 and 797 respectively. This trend no longer continued, when India started unlocking the states. The ease in the lockdown guidelines has resulted in a sudden surge in the number of cases especially in southern states like AP, Tamil Nadu and Karnataka. From Figure 4, it can be observed that more than 50000 cases were registered in July for 20 days. This has created chaos in the state health department and now there is a huge responsibility on the Government of AP to control the spread of COVID-19.

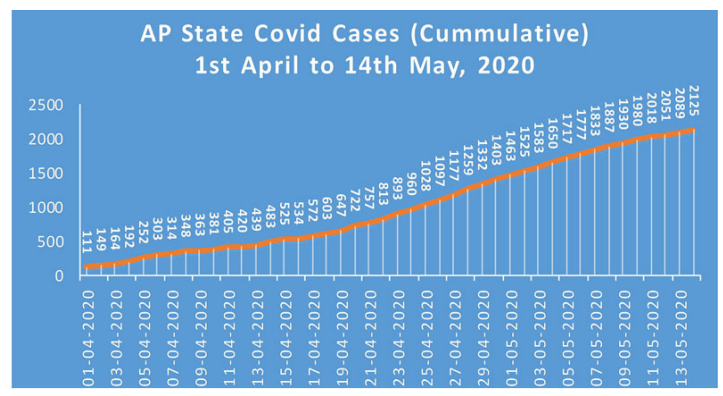

Figure 5: AP State COVID cases trend ${ }^{6}$.

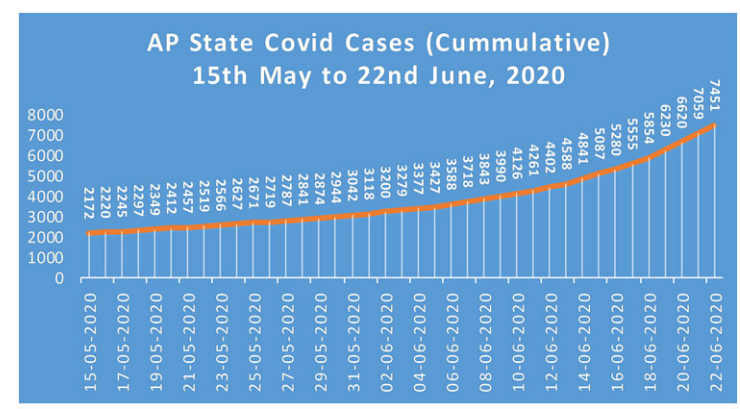

Figure 6: AP State COVID cases trend ${ }^{6}$.

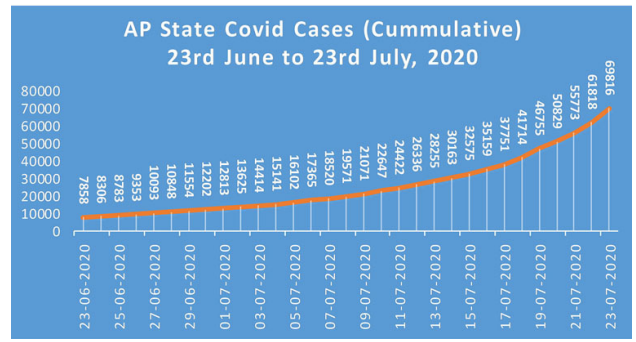

Figure 7: AP State COVID cases trend ${ }^{6}$.

Figure 5 represents the cumulative positive cases in the state from 1 April to 14 May 2020. Figure 6 shows the cumulative positive cases in the state from 15 May to 22 June 2020. Similarly, Figure 7 illustrates the cumulative positive cases in the state from 23 June 2020 to 23 July 2020. It can be noticed from Figures, that the number of confirmed cases after lockdown has become 20 times the count at the end of May 2020. As of today (23 July 2020), the state has 69816 confirmed COVID cases. However, the recovery rate of patients in the state is $47 \%$, while in the country it is $63 \%$. It indicates that the recovery rate is low compared to the country rate. So, the onus is on the government and people to bring down the increasing trend in the number of positive cases. Figure 8 shows the percentage of positive cases out of the tested samples per day. This is termed as Positivity rate. Initially, the positivity rate was very low under $2 \%$ from 14 April to 13 June 2020 . Now, it lies between 13 to $16 \%$ per day.

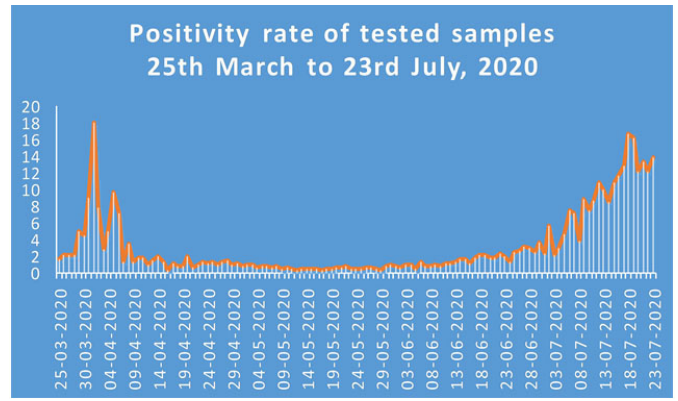

Figure 8: Positivity rate trend of tested samples ${ }^{6,7}$.

Figure 9 represents the trend of COVID death cases from 3 April to 23 July 2020 . It can be observed that currently, the death toll is nearly 15 times the value at the end of May 2020. This trend may continue with the increase in the number of confirmed cases. AP has $3 \%$ of its share in death count among the country. As of 23 July 2020, the number of cumulative deaths in the state is 884 .

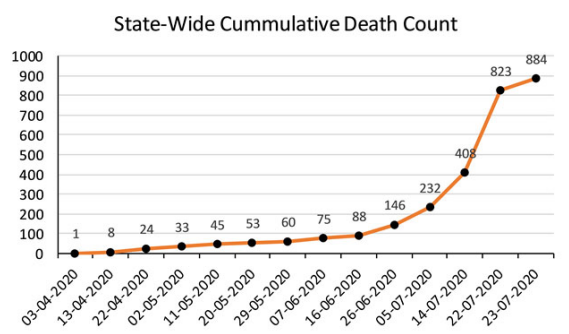

Figure 9: Trend of cumulative death count across state ${ }^{6,7}$. 


\section{Data Forecast}

In this study, we used the feature FORECAST.ETS in Microsoft EXCEL to estimate the future amount of AP state cases in the COVID-19 scenario. The Excel forecast chart uses an exponential smoothing algorithm to estimate a potential timeline value based on present values ${ }^{9}$. By using current data from 1 June 2020 to 23 July 2020, the forecast analysis is performed from 24 July 2020 to 14 September 2020. The forecast study is computed for approximately 55 days. Calculating the forecast estimate for more days (over three months) will lead to inconsistencies because different variables will change in the long term. For 55 days, lower and upper bound will indeed, help us to support the fluctuations.

\section{Projection of COVID-19 for AP-State}

\section{Projected Positive cases}

The projection is carried out from 24 July 2020 to 14 Sep 2020. Figure 10 represents the number of projected COVID positive cases in AP. Past trends are indicated with blue drop lines and forecast values are indicated with orange drop lines. The thin lines represent the lower and upper bounds of the forecast values. The confidence interval is set $95 \%$ to obtain the prediction. Figure 11 to illustrates the future trend of positive cases, data labels for alternate days are chosen to clearly show the numerical values. It is predicted that AP may experience a peak in the growth of COVID cases mid of September 2020.

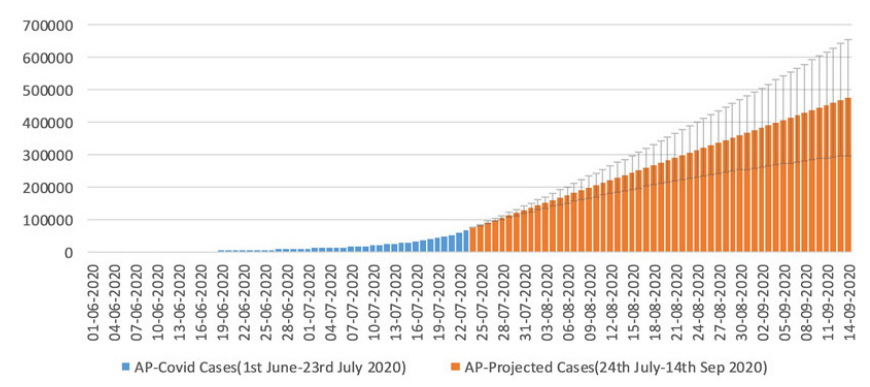

Figure 10: Projected COVID-19 Cases in $\mathrm{AP}^{8}$.

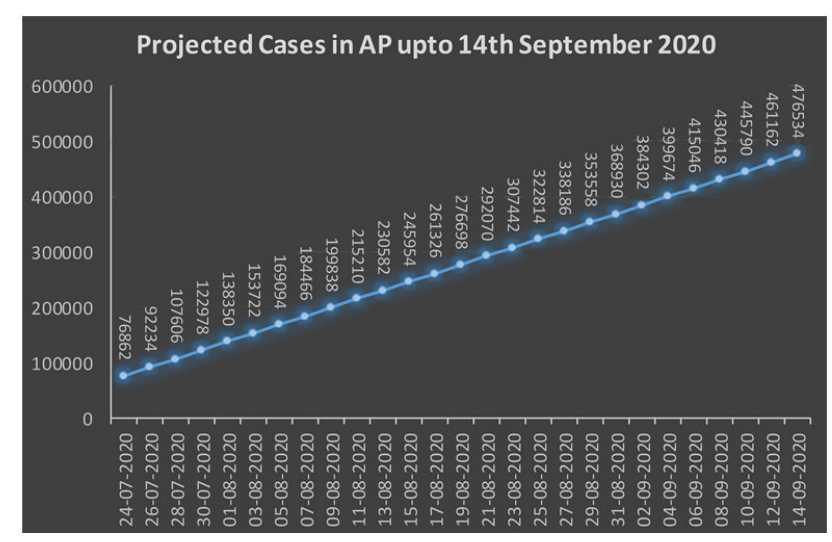

Figure 11: Projected COVID-19 Cases in $\mathrm{AP}^{8}$.

\section{Projected Positivity Rate (Out of tested sam- ples)}

Figure 12 represents the percentage of confirmed cases out of tested samples per day. Past trends are indicated with blue drop lines and forecast values are indicated with orange drop lines. Till June 2020, the percentage of confirmed cases is only $2 \%$. Now 23 July 2020, it has gone up and attained a value of $16 \%$. In the future, this value may further increase and go up to $25 \%$.

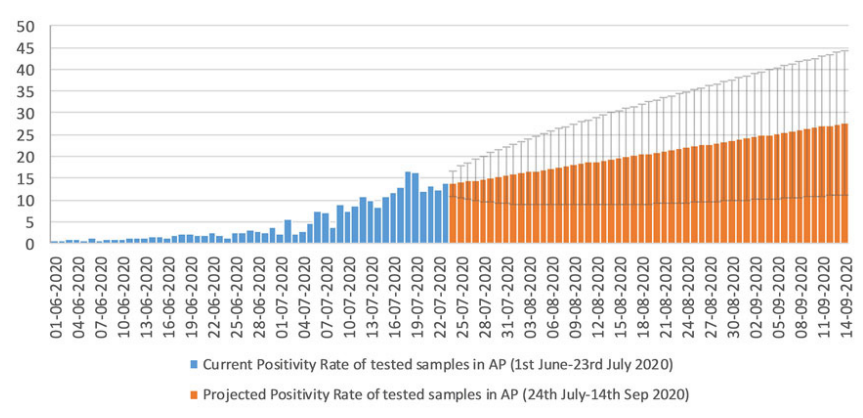

Figure 12: Projected Positivity Rate of tested samples in $\mathrm{AP}^{8}$.

\section{Projected Death Count}

As of 23 July 2020, the number of fatalities reported by AP State authorities is 884 . Figure 13 represents the projected death count in AP, the orange line shows the forecast value as 4263 by 14 September 2020. In the worst case, it may go up to 5287 (refer yellow colour line in the figure for upper bound) and with better prevention plan and strategies it may be controlled at 3240 (refer grey colour line in the figure for lower bound).

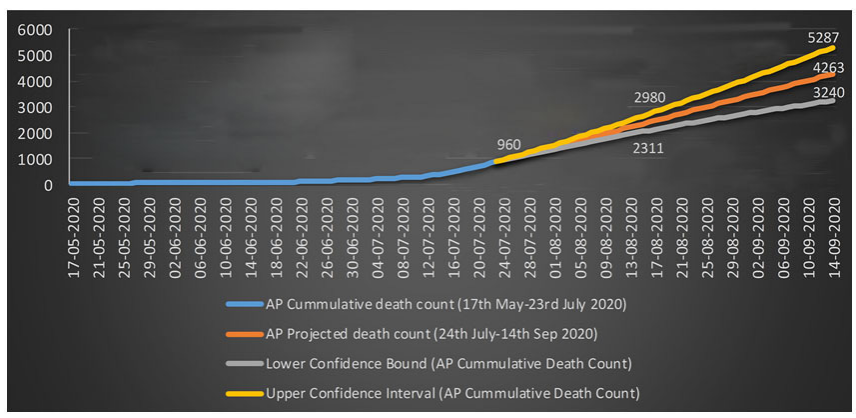

Figure 13: Projected Covid-19 Death Cases in $\mathrm{AP}^{8}$.

\section{DISCUSSION AND INTERPRETATION}

Andhra Pradesh is witnessing a surge in COVID-19 cases, with the total number of cases nearing 100000 and the death toll reaching 1000 . There have been no signs of the spread reducing in the state, with nearly 8000 new cases every day. The state has registered its first positive case on 12 March 2020 , while India on 30 January 2020 . The number of cumulative positive cases and the total death count in the state is 
quite low compared to India till the end of May 2020 (refer figure 1 and figure 2). Initially, Kurnool is the hotspot of the pandemic and now all the districts have affected due to virus. As of now, East Godavari district has registered the highest number of positive cases among all districts in the state (figure 3).

The Tablighi Jamaat issue in the mid of March 2020 and migrants workers from other states during unlocking are two major issues that had led to a spike in the number of registered cases. The state has well managed the control of cases in all phases of lockdown with an average number of cases less than 1000. But, after the declaration of unlocking phase by the Government of India the state has seen a sudden increase in the number of cases (figure 4). Currently, the state is witnessing an increasing trend in the number of positive cases (figure 7). The percentage of positive cases registered out of tested samples is maintained at $2 \%$ till mid of June 2020. After the return of migrant workers to the state, AP health department accelerated the testing. At the end of May 2020, the number of samples tested was 377197 . As of 23 July 2020, it has reached 1493879 approximately 15 times. The percentage of cases tested positive is very low at $2 \%$ till mid of June 2020 and it has increased to $16 \%$ (figure 8). While there has been an increase in positive cases in the state, AP has the highest million test numbers in the country ${ }^{10}$. The number of daily deceased cases is a single digit until mid-June 2020. Now, around 60 deaths are being registered every day. As of 23 July 2020, the total death count in AP is 884 (figure 9). The increase in the number of COVID cases and deaths has brought the need to analyze the current situation and project future scenarios. We have done the forecasting using excel ETS function. From the projections, it is estimated that AP would cross 400000 cases in the mid of September 2020 (figure 11). Based on the situation and control measures followed, it may vary between lower and upper bounds (figure 10). The number of samples tested positive has increased and the positivity rate varies between 10 to $17 \%$ (figure 12). The death count is also following a rising trend and the projected death toll is 4263 on 14 September 2020. It may vary between lower and upper bounds with a confidence interval of $95 \%$ (figure 13 ). Now, the AP state has many challenges ahead to prevent and control the massive spread of the virus.

\section{Recommendations:}

- At present, the AP state government is following a containment strategy to inhibit the spread of the virus. If necessary it is also imposing strict lockdown in many areas where the cases are high.

- Social distancing, wearing masks and controlling the wide movement of the public are among the prevention strategies.

- With the increase in cases, the hospital authorities are encouraging home treatment. Hence, monitoring the patients in home isolation is very crucial at this stage.

- Government has to advise all the private and public organizations to operate with a limited workforce or prefer work from home.

- Finally, social responsibility is the only promising factor to protect the nation from the pandemic.

\section{CONCLUSION}

Andhra Pradesh's newly formed state after bifurcation from Telangana is already in the process of building the capital city and develop the economy. However, due to COVID pandemic, it went into the financial crisis and now putting its best efforts to safeguard the people from this deadly disease. To bring the decaying economy on track, the government has started giving lockdown relaxations from 1 June 2020. The migration of workers and the process of normalization has resulted in a surge of cases. Now, the AP state has to face tough situations and plan accordingly to prevent the control of virus spread. The testing strategy adopted in the state plays a major role in the future to reduce the peak in the number of new cases. It helps in maintaining the low positivity rate and eradicate community transmission. Meticulous clinical management with medical readiness ensures a low mortality rate. Any individual or organization can succeed with proper planning about the future. In addition to the recommendation made above, it is advisable to forecast the numbers timeto-time and prepare the action plan for the better pandemic administration.

\section{ACKNOWLEDGEMENT}

Our heartfelt thanks to all authors, AP Government, Department of Health, medical and family welfare (HMFW) and Ministry of Health and family welfare (MoHFW), Indian Government whose reports/data are quoted and included in this paper.

Conflict of interest: The authors state that there is no conflict of interest.

Financial funding: No funding.

\section{REFERENCES}

1. Coronavirus Disease (COVID-19) Dashboard, https:// www. who.int/emergencies/diseases/novel-coronavirus-2019/technical-guidance/ accessed on 15 July 2020.

2. Coronavirus pandemic (COVID-19) https://www.worldometers. info/coronavirus/ accessed on 23 July 2020.

3. WHO Coronavirus Disease (COVID-19) Dashboard, https:// covid19.who.int/, accessed on 23 July 2020.

4. COVID-19 INDIA, Ministry of health and family welfare, Government of India, https://www.mohfw.gov.in/, accessed on 23 July 2020 . 
5. Andhra Pradesh: The rice granary of India, IBEF, http://www. ibef.org > Andhra-Pradesh-Infographic-June-2020.

6. COVID-19 Daily bulletins, Department of HMFW

7. http://hmfw.ap.gov.in/covid_19_dailybulletins.aspx accessed on 23 July 2020.

8. COVID-19 Andhra Pradesh, Department of HMFW

9. http://hmfw.ap.gov.in/covid_dashboard.aspx accessed on 23 July 2020.

10. Create a forecast in Excel for Windows, https://support.office. com/en-us/article/create-a-forecast-in-excel-for-windows22c500da-6da7-45e5-bfdc-60a7062329fd, accessed on 15 June 2020 .
11. Ramasamy K, Jayakumar S. The Trend of COVID-19 at Bengaluru: Prediction to Continue the Better Epidemic Management. International Journal of Current Research and Review. 2020; 12(13): 37-47.

12. With nearly 8000 new cases AP registers second highest spike after Maharashtra https://timesofindia.indiatimes.com/city/ visakhapatnam/with-nearly-8000-covid-19-cases-ap-registerssecond-highest-spike-after-maharashtra/articleshow/77138418. cms accessed on 24 July 2020. 